Document downloaded from:

http://hdl.handle.net/10251/49859

This paper must be cited as:

Carrillo Abad, J.; García Gabaldón, M.; Pérez Herranz, V. (2014). Treatment of spent pickling baths coming from hot dip galvanizing by means of an electrochemical membrane reactor. Desalination. 343:38-47. doi:10.1016/j.desal.2013.11.040.

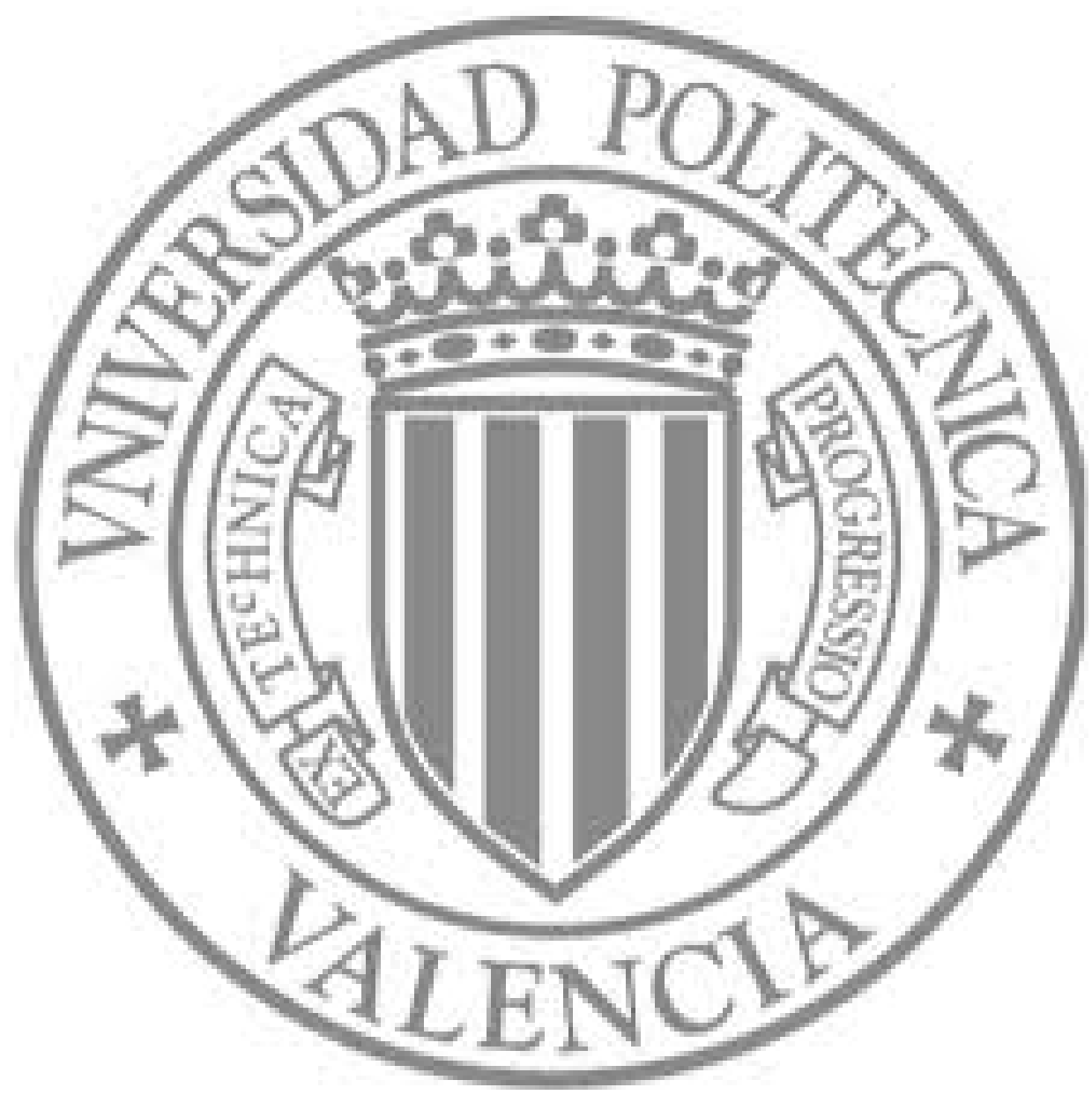

The final publication is available at

http://dx.doi.org/10.1016/j.desal.2013.11.040

Copyright Elsevier 


\title{
Treatment of spent pickling baths coming from hot dip galvanizing by means of an electrochemical membrane reactor
}

\author{
J. Carrillo-Abad, M. García-Gabaldón and V. Pérez-Herranz*
}

IEC Group, Departamento de Ingeniería Química y Nuclear, Universitat Politècnica de València, Camí de Vera s/n, 46900 València, Spain. P.O. Box 22012, E-46071

*Corresponding author: Tel.: +34 963877632; Fax: +34 963867639. E-mail addresses: vperez@iqn.upv.es (V. Pérez-Herranz)

Key words: Zinc, Iron, Cationic exchange membrane, Hot dip galvanizing, Anomalous codeposition, Zinc redissolution.

\begin{abstract}
The performance of a one (OCR) and a two-compartment electrochemical reactor in the presence of a cation-exchange membrane (CEM) for the zinc recovery present in the spent pickling baths is analyzed in this paper under galvanostatic control. These solutions, which mainly contain $\mathrm{ZnCl}_{2}$ and $\mathrm{FeCl}_{2}$ in aqueous $\mathrm{HCl}$ media, come from the hot dip galvanizing industry. The effect of the applied current, the dilution factor of the baths and the presence or absence of initial cathodic zinc is also studied.
\end{abstract}

For the 1:50 diluted spent bath, OCR experiments initially present higher values of the figures of merit than those obtained in the presence of the CEM since zinc is close to the cathode from the first electrolysis instants. However, at long electrolysis times, OCR presents zinc redissolution for all the current values tested due to the chlorine and iron presence close to the zinc deposits. In addition, the iron codeposition phenomenon is also observed in the OCR experiments when $\mathrm{pH}$ values are close to 2 . On the other hand, CEM experiments become very similar to the OCR experiments at long time values since the CEM under these experimental conditions prevents zinc redissolution phenomenon and also iron codeposition. 
When the 1:50 diluted bath is concentred to 1:10, OCR experiments present the same tendency as that observed for the 1:50 dilution factor but the effect of zinc redissolution is increased due to the greater amount of chlorine generated in the anode. Under these experimental conditions, iron deposition has also been observed in the presence of the cation-exchange membrane as the rate of zinc deposition is greater than that of zinc transport through the membrane, and the zinc/iron ratio in the cathodic compartment is not high enough to prevent iron codeposition. In both cases, the $\mathrm{pH}$ values when iron codeposits with zinc is close to 2 and the zinc/iron ratio is below 0.6. The presence of initial zinc in the cathodic compartment of the electrochemical reactor enhances the reactor performance since allows the zinc-iron separation in one single step and avoids the zinc redissolution phenomenon.

\section{1- Introduction}

The pickling step, previous to the galvanized process, consists of attacking the surface of the pieces with $\mathrm{HCl}$ in order to clean them from rust and impurities. This process generates a succession of effluents containing, among other substances, high concentrations of $\mathrm{ZnCl}_{2}, \mathrm{FeCl}_{2}$ and $\mathrm{HCl}$ [1]. The composition of these baths depends on the kind of the pieces cleaned. If the pieces pickled are new ones, an iron rich effluent will be obtained, whose typical composition is 100-160 g/l of Fe, 5-10 g/l of $\mathrm{Zn}$ and 30$50 \mathrm{~g} / \mathrm{l}$ of $\mathrm{HCl}$; but if these pieces have previously been galvanized, the effluent would be rich in zinc and its typical composition would be 10-20 g/1 of Fe, 80-230 g/l of Zn and 10-30 g/1 of HCl. Finally, if both kinds of pieces are treated, a mixture effluent will be obtained, whose typical composition is $80-120 \mathrm{~g} / \mathrm{l}$ of Fe, 20-60 g/l of $\mathrm{Zn}$ and 30-50 g/l of $\mathrm{HCl}$ [2]. The production of the spent pickling bath gives rise to an environmental problem that has to be solved due to the hazardous nature of the effluents [3]. However, due to the complexity of the hydrochloric acid effluents, which are usually found as chloro-complexes, the development of an adequate treatment for this effluent is very difficult. The traditional treatment methods [4] based on a precipitation-filtration technique result inefficient and, as a result, many different techniques have been suggested [5], such as liquid-liquid extraction [6] or anionic resins [7]. Nevertheless, these processes have the disadvantage of needing another step to obtain a valuable product. 
In this sense, a treatment method that allows zinc recovery from the spent pickling bath in one single step by means of an electrochemical reactor is studied in this paper. In a previous work [8], the authors carried out an electrochemical study of the spent bath to obtain the electrochemical processes kinetics. Subsequently, a one cell electrochemical batch reactor was used in potentiostatic and galvanostatic mode $[9,10]$ in order to determine the viability of zinc recovery. During these experiments, zinc redissolution was observed at long time values for all the experimental conditions. This process is related to the synergistic effect of iron ions and dissolved chlorine gas that attacks zinc deposits causing their oxidation $[11,12]$. As a consequence, the effect of the presence of an anionic exchange membrane (AEM) in the electrochemical reactor was also evaluated [13]. The AEM acted as a barrier for the chlorine gas that could not reach the cathodic compartment preventing the zinc redissolution phenomenon. However, in the absence of chlorine, iron began to codeposit with zinc following an anomalous codeposition phenomenon [14-16] as although iron is more noble than zinc, it deposits preferentially.

In order to prevent iron codeposition, in this paper the AEM is changed to a cationic exchange membrane (CEM), NAFION-117. The spent pickling baths are placed in the anodic compartment since the NAFION-117 membrane permits the zinc pass to the cathodic compartment preferentially over iron. This is associated with the fact that divalent iron is oxidized to trivalent iron in the anodic compartment and this membrane retains preferentially trivalent cations [17-19]. Therefore, the results obtained in the absence of CEM and those in the membrane reactor with the CEM will be analyzed and compared by means of the figures of merit $[20,21]$ (fractional conversion, current efficiency, space-time yield and specific energy consumption). Moreover, the effect of the applied current and the presence or absence of initial zinc in the cathodic compartment will also be evaluated. It is worth to note that this latter is added in the cathodic compartment to try to minimize iron codeposition. 


\section{2- Experimental procedure}

The one cell reactor (OCR) and the membrane reactor used in this work were well defined in our previous works $[9,13]$. However, a scheme of the two reactors employed in this work together with the main reactions taking place on both electrodes is presented in Fig. 1 and in the "Results and discussion" point. In the one cell reactor, 100 $\mathrm{cm}^{3}$ of spent pickling solution was used whereas an equal volume $\left(250 \mathrm{~cm}^{3}\right)$ of anolyte and catholyte was poured in their respective chamber after cell assembly in the membrane reactor. The same $\mathrm{Ag} / \mathrm{AgCl}$ reference electrode and graphite cathode and anode have been used in both reactors. Both cathode and anode were totally immersed in the solution and they were symmetrically placed with respect to the membrane surface. As mentioned previously, the membrane used in the CEM experiments was a NAFION 117. The anode and cathode were made of two cylindrical graphite bars with an effective area of $14.15 \mathrm{~cm}^{2}$.

In the membrane reactor experiments, the 1:50 or the 1:10 diluted spent pickling bath was placed in the anodic compartment and a synthetic solution composed of $0.1 \mathrm{M} \mathrm{HCl}$ (CEM-1) or $0.1 \mathrm{M} \mathrm{HCl}$ and $0.1 \mathrm{M} \mathrm{ZnCl}_{2}$ (CEM-2) was placed in the cathodic one. The synthetic solutions containing $\mathrm{HCl}$ and/or $\mathrm{ZnCl}_{2}$ were made from analytical grade reagents and distilled water. All experiments were made at room temperature. The spent pickling baths used in this work come from a valencian galvanizer industry and its composition appears in Table 1.

Experiments were performed at different applied currents, which ranged from $-450 \mathrm{~mA}$ to $-1000 \mathrm{~mA}$. The equipment used for the electrolysis experiments was an Autolab PGSTAT20 potentiostat/galvanostat. Potential, cell voltage, current, $\mathrm{pH}$ and temperature were recorded during the electrowinning. Samples of $1 \mathrm{ml}$ were taken from the reactor every 30 minutes. In the CEM experiments, the samples were taken from both compartments. This sampling volume has been taken into account and all the figures of merit have been recalculated. Zinc and iron determination was performed by atomic absorption spectrophotometry (AAS) as described in our previous works $[9,10$, 13]. The determination of zinc is performed on a Perkin-Elmer model Analyst 100 atomic absorption spectrophotometer using a zinc hollow cathode lamp at $213.9 \mathrm{~nm}$ wavelength, $0.7 \mathrm{~nm}$ spectral bandwidth and an operating current of $5 \mathrm{~mA}$. To measure 
iron concentration it is used the same equipment changing the $\mathrm{Zn}$ hollow lamp for a $\mathrm{Fe}$ hollow lamp, the wavelength used is $248.3 \mathrm{~nm}$, the applied operating current is $5 \mathrm{~mA}$ and the spectral bandwidth is $0.2 \mathrm{~nm}$. 


\section{3- Results and discussion}

First of all, a summary of the main reactions that can take place on both electrodes are presented:

\section{Cathodic reactions}

$\underline{Z^{+2}}(a q)+2 \cdot e^{-} \rightarrow \mathrm{Zn}(\mathrm{s})$

$\underline{\mathrm{Fe}^{+2}(\mathrm{aq})+2 \cdot e^{-} \rightarrow \mathrm{Fe}(\mathrm{s})}$

$\mathrm{Fe}^{+3}(a q)+1 \cdot e^{-} \rightarrow \mathrm{Fe}^{+2}(a q)$

$\underline{2 H^{+}(a q)+2 \cdot e^{-} \rightarrow H_{2}}(g)$

\section{Anodic reactions}

$\underline{2 \cdot \mathrm{Cl}^{-}(a q) \rightarrow \mathrm{Cl}_{2}}(\mathrm{~g})+2 \cdot e^{-}$

$\underline{2 \cdot H_{2}} \underline{O}(\mathrm{l}) \rightarrow 4 \cdot H^{+}(a q)+\cdot \mathrm{O}_{2}(g)+4 \cdot e^{-}$

$\underline{\mathrm{Fe}^{+2}(a q)+\rightarrow \mathrm{Fe}^{+3}(a q)+e^{-}}$

In the following points, the performance of both reactors will be studied by means of the following figures of merit [20, 21]:

Fractional conversion:

$$
X(t)=\frac{C_{0}-C(t)}{C_{0}}
$$

Where $\mathrm{C}_{0}$ is the initial concentration of the species of interest and $\mathrm{C}(\mathrm{t})$ is its concentration at a certain instant of time.

Current efficiency:

$\phi(t)=\frac{n \cdot F \cdot\left(C_{0}-C(t)\right) \cdot V}{\int_{0}^{t} I(t) d t} \cdot 100$

Where $\mathrm{n}$ is the number of electrons exchanged in the metal deposition, $\mathrm{F}$ is the Faraday's constant, $\mathrm{V}$ is the reactor volume and $\mathrm{I}(\mathrm{t})$ is the applied current at a certain instant of time.

Space-time yield: 
$\eta(t)=\frac{M \cdot\left(C_{0}-C(t)\right)}{t} \quad\left(\mathrm{~g} \cdot \mathrm{l}^{-1} \cdot \mathrm{h}^{-1}\right)$

Where $\mathrm{M}$ is the atomic weight of the species of interest and $\mathrm{t}$ is a given instant time.

Specific energy consumption:

$E_{s}(t)=\frac{\int_{0}^{t} U(t) \cdot I(t) d t}{M \cdot V \cdot C_{0} \cdot X(t) \cdot 3600} \quad\left(\mathrm{~kW} \cdot \mathrm{h} \cdot \mathrm{kg}^{-1}\right)$

Where $\mathrm{U}(\mathrm{t})$ is the cell potential at a given instant time.

\section{1-1:50 diluted spent pickling bath}

Fig. 2 shows the zinc fractional conversion $\left(\mathrm{X}_{\mathrm{Zn}}\right)$ profile of the two different electrochemical reactors for two different values of the applied current when processing the 1:50 diluted spent bath. $\mathrm{X}_{\mathrm{Zn}}$ increases with the applied current for both reactors. As expected, the one cell reactor presents higher zinc conversion values than those obtained by the membrane reactor for all the applied current values during the initial electrolysis instants. This is explained by the fact that the volume of the OCR is 2.5 times lower than that of the CEM-1, therefore, for the same applied current, the OCR's zinc fractional conversion has to be higher. However, zinc redissolution process $[11,12]$ appears in the one cell reactor for all the applied currents due to the chlorine and iron presence close to zinc deposits. On the other hand, as the cation exchange membrane prevents zinc redissolution process, CEM-1 presents higher $\mathrm{X}_{\mathrm{Zn}}$ values at longer times despite of its greater reactor volume.

The iron conversion profile is shown in Fig. 3 for the same experimental conditions as those explained above. It is noteworthy that iron does not deposit with zinc in a normal way but following the anomalous codeposition process $[15,16,22]$. Therefore, in the case of the OCR experiments, iron deposition begins when zinc concentration diminishes, approximately, to 50\%. This agrees with the model suggested by Dahms et al. [23] who proposes that zinc inhibits iron deposition by the formation of a hydroxide film on the cathode surface. Therefore when zinc-iron ratio is low, the amount of zinc ions near the cathode diminishes, then, the film becomes weaker and iron begins to deposit. Moreover, iron conversion increases with the applied current. On the other 
hand, when the CEM-1 reactor is used, no iron deposition is observed since iron must pass through the membrane before being deposited in the cathodic chamber. In addition, as iron is being oxidized in the anodic compartment and the membrane retains trivalent ions preferentially [17-19], iron presence in cathodic compartment is reduced and, thus, the zinc-iron ratio in the cathodic chamber is not sufficiently low to permit iron codeposition.

The bulk solution $\mathrm{pH}$ was measured over all the experiment time as can be observed in Fig. 4. It is worth to note that the initial $\mathrm{pH}$ for OCR and CEM is not the same since in CEM experiments a $0.1 \mathrm{M} \mathrm{HCl}$ solution is placed in the cathodic compartment. For all the cases under study, the $\mathrm{pH}$ increases with time due to the protons consumption related to hydrogen evolution reaction. On the other hand, in the OCR experiments, a sharp $\mathrm{pH}$ increase is observed when iron begins to codeposit with zinc. This fact may be associated with the $\mathrm{pH}$ effect on the iron deposition observed in our previous works [24], where the inhibition of iron deposition at low $\mathrm{pH}$ solutions was observed.

In Fig. 5, the zinc current efficiency evolution $\left(\phi_{\mathrm{Zn}}\right)$ with time can be observed for the same experimental conditions as those explained previously. In the OCR experiments, $\phi_{\mathrm{Zn}}$ decreases with the applied current owing to an increase in the rate of parallel reactions, like the hydrogen evolution reaction (HER). On the other hand, the CEM-1 experiments initially show very similar current efficiency values for both applied current values since none of them have zinc in the cathodic compartment at the beginning of the experiment. However, at long time values, the higher transport rate together with the higher zinc deposition rate make the $\phi_{\mathrm{Zn}}$ values be higher for $-700 \mathrm{~mA}$ than those obtained at $-450 \mathrm{~mA}$. If $\phi_{\mathrm{Zn}}$ is compared for both reactors, the one cell reactor initially has better results due to the fact that in the CEM-1 experiments zinc is absent from the cathodic compartment at the initial electrolysis moments and, therefore, HER is the main reaction in these moments. In addition, another process that consumes energy, diminishing $\phi_{\mathrm{Zn}}$ in the CEM-1 experiments, is the transport of the ions through the membrane from the anodic chamber to the cathodic one. Nevertheless, at long time values, the membrane reactor presents higher $\phi_{\mathrm{Zn}}$ values since no redissolution phenomenon appears in this reactor due to chlorine absence in the cathodic chamber. 
Moreover, there is no iron codeposition when the CEM is used with the subsequent energy saving.

Regarding zinc space-time yield, $\eta$, its evolution with time for the same experimental conditions as those mentioned previously is shown in Fig. 6. For both cases, $\eta$ increases with the applied current because of the turbulence promoting action of hydrogen evolution, the increase of the electrode surface roughness and the higher velocity of the electrochemical reactions [9]. On the other hand, comparing the results obtained for both reactors, OCR experiments initially presents higher $\eta$ due to the lower reactor volume. In addition, the low ionic transport rate through the membrane helps to obtain lower $\eta$ values since this step limits the zinc deposition rate. It is worth to note that for the OCR case, $\eta$ increases sharply in the initial period due to the nucleation of zinc onto the graphite electrode, which causes a decrease in the electrode resistance. However, $\eta$ decreases with time as a consequence of zinc depletion from the solution. On the other hand, CEM-1 does not present this behavior since zinc is absent in the cathodic compartment at the initial electrolysis times but as it continuously arrives from the anodic compartment, $\eta$ remains practically constant.

Fig. 7 presents the evolution of the specific energy consumption, $E_{S}$, with time for the same experimental conditions as those explained in Fig. 2. For the OCR experiments, the specific energy consumption increases with time as a consequence of the zinc depletion from the solution. It is worth to note that an increase with the applied current is detected when zinc redissolution phenomenon appears at 180 mins. This is related to the fact that the specific energy consumption evolution is directly proportional to the fractional conversion and inversely proportional to the current efficiency. Therefore, the opposite tendencies of $\mathrm{X}_{\mathrm{Zn}}$ and $\phi_{\mathrm{Zn}}$ observed for both applied currents are the cause of the similarity of the $E_{s}$ values obtained for the OCR experiments during the firsts 180 minutes. However, for CEM-1 experiments the tendency is the opposite: during the first 100 and 150 minutes of electrolysis, HER is the main reaction for the applied currents of -700 and $-450 \mathrm{~mA}$, respectively, which consumes high amounts of energy but as the zinc coming from the anodic compartment covers completely the graphite electrode surface the HER rate decreases since zinc acts as HER inhibitor [16]. Finally, at long electrolysis times, the prevention of zinc redissolution phenomenon and iron codeposition makes $E_{S}$ values be very similar for both reactors. It is worth to mention 
that $E_{S}$ values for CEM-1 are initially higher than those obtained for the OCR experiments, in spite of the energy consumption related to the iron deposition in the OCR assays. This fact is associated with the ohmic drop produced by the presence of the membrane.

\section{2- 1:10 diluted spent pickling bath}

In order to obtain results closer to the real spent pickling baths, in this point, more concentrated samples are tested. The selected dilution factor is 1:10 because it is the most concentrated solution that permits zinc deposition in the OCR experiments. In more concentrated solutions, chlorine gas together with the iron species inhibits zinc deposition from the beginning of the electrolysis. Moreover, two different solutions in the cathodic chamber of the CEM experiments are tested: $0.1 \mathrm{M} \mathrm{HCl}(\mathrm{CEM}-1)$ and 0.1 $\mathrm{M} \mathrm{HCl}+0.1 \mathrm{M} \mathrm{ZnCl} 2(\mathrm{CEM}-2)$.

Fig. 8 shows the comparison of the zinc conversion profile between the one cell reactor (OCR) and the membrane reactor for both acidic solutions poured in the cathodic chamber (CEM-1 and CEM-2) and for an applied current of -1A. OCR experiments initially present higher $\mathrm{X}_{\mathrm{Zn}}$, as expected, since not only all the zinc is available for its deposition from the beginning of the electrolysis experiments but also this reactor has a lower volume and, therefore, the initial amount of zinc is lower. However, at $180 \mathrm{~min}$ zinc conversion arrives to a maximum value beyond which it begins to decrease due to the chlorine attack of the formed zinc deposits. Comparing CEM-1 and CEM-2, higher zinc conversion values are obtained for CEM-2 despite of its greater amount of initial zinc as the zinc that is present in the cathodic compartment from the beginning of electrolysis enhances the deposition of the zinc coming from the anodic chamber. Moreover, no zinc redissolution phenomenon was observed for any of the CEM assays since, as mentioned above, the membrane acts as a barrier against the chlorine formed in the anodic compartment. Comparing these values with those obtained for the 1:50 diluted bath (Fig. 2), high conversion values are obtained for the less concentrated solution, due to the lesser amount of zinc present in the reactor.

The iron conversion results and the zinc-iron ratio evolution are shown in Fig. 9 and 10, respectively. In the case of the OCR experiments, iron deposition follows the same 
tendency as that observed in Fig. 3, that is, when zinc conversion reaches approximately a $50 \%$ and the zinc-iron ratio decreases to values lower than 0.6 , iron begins to deposit. It is worth noting that when no zinc is placed in the cathodic compartment, iron codeposits with zinc from the beginning of the electrolysis (CEM-1 experiments). This is related to the fact that for these experiments, a higher amount of iron passes through the membrane. In the case of the 1:50 diluted bath, iron did not codeposit despite of the zinc absence in the cathodic compartment (Fig. 2) because the zinc-iron ratio was maintained sufficiently high to prevent iron codeposition as the rate of iron transport thorough the membrane was so low to permit iron condeposition. Therefore, in the 1:10 diluted spent baths, the higher iron concentration increases its transport rate through the membrane and, therefore, the zinc-iron ratio could diminish up to the point that the zinc hydroxide film becomes weaker permitting iron codeposition. As it can be seen in Fig. 10, for the CEM-1 experiment, the zinc-iron ratio remains lower than 0.6 during all the electrolysis. In this sense, when zinc is initially present in the cathodic compartment (CEM-2 experiments) no iron deposition has been observed since the presence of this zinc in the cathodic compartment maintains the zinc-iron ratio sufficiently high to prevent iron codeposition since, as shown in Fig. 10, for CEM-2 experiments, the zinciron ratio is higher than 0.6 for all time. Therefore, a relationship may be suggested between the zinc-iron ratio and the iron codeposition phenomenon: iron codeposition begins when zinc-iron ratio diminishes below 0.6 .

In Fig. 11, the $\mathrm{pH}$ profile for the same experimental conditions as those presented in Fig. 8 is shown. Once more, the initial $\mathrm{pH}$ value depends on the reactor employed. However, in this case, the 1:10 diluted spent bath is more acid than the $0.1 \mathrm{M} \mathrm{HCl}$ solution. For all the cases under study, the $\mathrm{pH}$ increases with time as a consequence of the hydrogen evolution reaction. As observed previously in OCR and CEM-1 experiments, Fig. 4, as iron codeposition begins, a sharp increase of the $\mathrm{pH}$ value is observed. It is worth to note that the $\mathrm{pH}$ values measured when iron codeposition is detected are close to 2 .

The zinc current efficiency evolution is presented in Fig. 12 for the same experimental conditions as those shown in Fig. 8. The lowest $\phi_{\mathrm{Zn}}$ values are obtained for the OCR experiments due to the zinc redissolution process, which together with other parallel reactions (HER process and iron codeposition) diminishes $\phi_{\mathrm{Zn}}$. Although zinc 
redissolution phenomenon is not observed in OCR until 180min the low fractional conversion values achieved in this reactor, despite of its lower volume, suggest that the chlorine attack of zinc deposits takes place from the beginning of the electrolysis. Therefore, both reactions (zinc deposition and zinc redissolution) compete from the beginning of the experiments. Thus, for time values lower than $180 \mathrm{~min}$, the zinc deposition rate is higher than the zinc redissolution rate and, as a consequence, the zinc fractional conversion grows, whereas for longer times zinc redissolution rate becomes higher than the zinc deposition rate and the zinc fractional values start to decrease. On the other hand, CEM-2 presents the highest $\phi_{\mathrm{Zn}}$ values since iron does not codeposit in this case thanks to the fact that zinc concentration remains sufficiently high so as to inhibit iron deposition, thus saving a great amount of energy. In addition, the presence of zinc in the cathodic compartment from the beginning of the electrolysis favours the deposition of the zinc coming from anodic compartment, as mentioned previously, increasing the current efficiency. Comparing these results with those obtained for the 1:50 diluted bath, it can be observed that increasing the concentration of the bath favours the current efficiency since this higher concentration permits a higher ionic transport through the membrane. In addition, the shape of the profile for the CEM-1 experiment also changes. This fact may be due to a change in the importance of the different reactions involved, that is, this higher ion transport permits a higher zinc deposition and, therefore, a higher zinc current efficiency. On the other hand, the OCR experiment presents worse results in terms of current efficiency when the concentration of the spent bath is increased. This fact is related to the chlorine attack of zinc deposits since a higher chloride concentration permits a higher chlorine formation and, then, a higher oxidation rate of zinc deposits is observed.

The evolution with time of the zinc space-time yield $(\eta)$ for both reactors and both initial cathodic solutions is shown in Fig. 13. Comparing the behavior of both reactors during the first instants of the electrolysis, CEM-2 and OCR present very similar values despite of the lower OCR volume since the initial zinc amount in CEM-2 is higher than in OCR and, in both cases, the zinc is present close to the cathode. However, zinc depletion in the OCR experiments makes $\eta$ be lower than those obtained for CEM-2, where zinc continuously passes from the anodic compartment. In addition, at long electrolysis time, $\eta$ diminishes for the OCR experiments up to the point that its value becomes the lowest. This fact is related to the zinc redissolution phenomenon. 
Comparing CEM experiments, CEM-2 presents higher values than CEM-1 as not only CEM-2 has a greater zinc amount but also the presence of zinc in the cathodic compartment from the beginning of the electrolysis permits a higher zinc deposition rate. Furthermore, the increase of the spent bath concentration favours the behaviour of both reactors since an increase in zinc concentration causes an increase of zinc spacetime yield.

Finally, the evolution with time of the zinc specific energy consumption for the experimental conditions mentioned above is shown in Fig. 14. In this case, CEM-2 and OCR experiments initially present closer values, which are lower than those obtained in the CEM-1 experiments since, in the first two cases, zinc is present from the beginning of the electrolysis near the cathode. Therefore, zinc deposition is the main reaction from the initial electrolysis moments and lower amounts of energy are consumed by the HER process. However, as soon as zinc redissolution phenomenon and iron codeposition begin, the value of $E_{S}$ for OCR abruptly increases since iron deposition has an additional energetic cost to the amount of energy spent in the zinc deposition process. In addition, the zinc redissolution phenomenon must cause an increase in the energy consumed since part of the energy is wasted in the redeposition of the zinc previously oxidized. Although for time values below 100 minutes, $E_{S}$ values for OCR and CEM-2 are very close, they are slightly lower for CEM-2 since the membrane prevents zinc redissolution phenomenon and the initial zinc in the cathodic chamber avoids iron codeposition saving great amounts of energy. In addition, $\mathrm{E}_{\mathrm{S}}$ for the CEM-2 experiment remains practically constant as zinc comes continuously from the anodic compartment. If both solutions are compared, for the OCR reactor the $E_{S}$ values are slightly lower for the 1:10 spent baths since an increase in ions concentration increases the solution conductivity. However, as mentioned above, this increase in the bath concentration involves a higher chloride concentration and, therefore, the effect of zinc redissolution phenomenon will be higher causing a greater increase of $E_{S}$ values. Regarding the CEM experiments, the increase in the concentration of the bath favours the ionic transport through the membrane and, therefore, a greater presence of ions is achieved near the cathode. This fact causes the increase of the solution conductivity and, then, lower $\mathrm{E}_{\mathrm{s}}$ values are obtained. 


\section{4- Conclusions}

Two different kinds of electrochemical reactors were used to study the zinc recovery coming from the hot dip galvanizing spent pickling baths. These baths mainly consist of $\mathrm{ZnCl}_{2}$ and $\mathrm{FeCl}_{2}$ in $\mathrm{HCl}$ media. The first reactor was formed by one single cell (OCR experiments) whereas the second one was based on two different compartments with a cation-exchange membrane (CEM) placed between them. The different figures of merit were calculated for both types of reactors in order to evaluate their behaviour and to select the best recovery conditions. Moreover, the effect of the applied current, the dilution factor and the presence or absence of initial cathodic zinc was also studied.

For the 1:50 diluted spent pickling bath, the CEM experiments initially presented lower zinc conversion, current efficiency, space-time yield and higher specific energy consumption because zinc must pass through the membrane previously to its deposition. This fact allowed HER to be the main reaction during the first instants of the electrolysis. In addition, the membrane produced an ohmic drop that, together with the low ion concentration in the cathodic compartment were related to the high values of $E_{S}$. However, since the presence of the CEM prevented the chlorine attack of the zinc deposits and also the iron codeposition, the figures of merit of the reactor in the presence of the CEM became similar to those obtained in its absence at the final instants of the electrolysis experiments. Regarding iron codeposition, a slight $\mathrm{pH}$ increase was observed when it began, probably related to the inhibition of iron deposition at low $\mathrm{pH}$ values.

In the second part of this paper, more concentrated baths were studied (1:10 diluted spent baths). In the OCR experiments, zinc redissolution phenomenon was very important making $\mathrm{X}_{\mathrm{Zn}}$ return to their initial levels, and sharply diminishing the values of the rest of the figures of merit. Whenever the results obtained in the absence of initial zinc in the cathodic compartment are compared for the different dilution factors, it is concluded that due to the high rate of zinc deposition and the greater iron transport rate through the membrane, in the case of the 1:10 diluted spent bath, iron codeposits with zinc since in this case, the ratio zinc-iron is not sufficiently high. In addition, when iron deposition began, a zinc-iron ratio below 0.6 together with a $\mathrm{pH}$ values above 2 was observed. Regarding the effect of placing initial zinc in the cathodic compartment not 
only improved all the figures of merit values but also prevented iron codeposition. Therefore, this option appears as an interesting alternative as it permits the zinc-iron separation in only one step and, in addition, the CEM also avoids the chlorine presence near the cathode. 


\section{Acknowledgements}

The authors want to express their gratitude to the Generalitat Valenciana for a postgraduate grant (GV/2010/029) and to the Ministerio de Economía y Competitividad for financing the project number CTQ2012-37450-C02-01/PPQ 


\section{References}

[1] U. Kerney, Treatment of spent pickling acids from hot dip galvanizing Resources, Cons. and Rec., 10 (1994) 145-151.

[2] Samaniego-Peña, H.; Ortiz-Uribe, I.; San Román-San Emeterio, M.F., Valoración de efluentes de decapado ácido metálico. Recuperación de zinc, $\mathrm{PhD}$ Thesis, Universidad de Cantabria (2006).

[3] C. Stocks, J. Wood, S. Guy, Minimisation and recycling of spent acid wastes from galvanizing plants, Res., Cons. and Rec., 44 (2005) 153-166.

[4] G. Csicsovszki, Tamás Kékesi, Tamás I. Török, Selective recovery of Zn and Fe from spent pickling solutions by the combination of anion exchange and membrane electrowinning techniques, Hydrometallurgy, 77 (2005) 19-28.

[5] M. Regel-Rosocka, A review on methods of regeneration of spent pickling solutions from steel processing, J. of Hazard. Mater., 177 (2010) 57-69.

[6] M. Regel-Rosocka, M. Wisniewski, Selective removal of zinc(II) from spent pickling solutions in the presence of iron ions with phosphonium ionic liquid Cyphos IL 101, Hydrometallurgy 110 (2011) 85-90.

[7] E. Marañón, Y. Fernández, F. J. Suárez, F. J. Alonso, H. Sastre, Treatment of Acid Pickling Baths by Means of Anionic Resins, Ind. \& Eng. Chem. Res. 39 (2000) 3370-3376.

[8] M. García-Gabaldón, J. Carrillo-Abad, V. Pérez-Herranz, E. M. Ortega-Navarro, Electrochemical Study of a Simulated Spent Pickling Solution., Int. J. Electrochem. Sci., 6 (2011) 506-519.

[9] J. Carrillo-Abad, M. García-Gabaldón, E. M. Ortega-Navarro, V. Pérez-Herranz, Electrochemical recovery of zinc from the spent pickling baths coming from the hot dip galvanizing industry. Potentiostatic operation, Sep. and Purif. Technol., 81 (2011) 200-207.

[10] J. Carrillo-Abad, M. García-Gabaldón, V. Pérez-Herranz, Electrochemical Recovery of Zinc from the Spent Pickling Solutions Coming from Hot Dip 
Galvanizing Industries. Galvanostatic Operation, Int. J. Electrochem. Sci., 7 (2012) 5442-5456.

[11] O.Caldwell-Ralston, Electrolytic Deposition and Hydrometallurgy of Zinc, McGraw-Hill Book Company (ed.), 1921, 124-138.

[12] B. K. Thomas, D. J. Fray, The effect of additives on the morphology of zinc electrodeposited from a zinc chloride electrolyte at high current densities, J. of Appl. Electrochem., 11 (1981) 677-683.

[13] J. Carrillo-Abad, M. García-Gabaldón, E. M. Ortega-Navarro, V. Pérez-Herranz, Recovery of zinc from spent pickling solutions using an electrochemical reactor in presence and absence of an anion-exchange membrane: Galvanostatic operation, Sep. and Purif. Technol., 98 (2012) 366-374.

[14] E. Gómez, E. Peláez, E. Vallés, Electrodeposition of zinc+iron alloys: I. Analysis of the initial stages of the anomalous codeposition, J. of Electroanal. Chem., 469 (1999) 139-149.

[15] Z. Zhang, W. H. Leng, H. B. Shao, J. Q. Zhang, J. M. Wang, C. N. Cao, Study on the behavior of Zn-Fe alloy electroplating, J. of Electroanal. Chem. 516 (2001) 127-130.

[16] P. Díaz-Arista, O. R. Mattos, O. E. Barcia, F. J. Fabri Miranda, ZnFe anomalous electrodeposition: stationaries and local pH measurements, Electrochim. Acta 47 (2002) 4091-4100.

[17] R. F. la Costa, J. Z. Ferreira, C. Deslouis, Electrochemical study of the interactions between trivalent chromium ions and Nafion-117 perfluorosulfonated membranes, J. of Membr. Sci., 215 (2003) 115-128.

[18] T. Okada, Y. Ayato, M. Yuasa, I. Sekine, The effect of impurity cations on the transport characteristics of perfluorosulfonated ionomer membranes, The J. of Phys. Chem., 103 (1999) 3315-3322. 
[19] M. Taky, G. Pourcelly, C. Gavach, A. Elmidaoui, Chronopotentiometric response of a cation exchange membrane in contact with chromium(III) solutions, Desalination 105 (1996) 219-228.

[20] García-Gabaldón, M.; Pérez-Herranz, V.; García-Antón, J.; Guiñón, J.L., Electrochemical recovery of tin and palladium from the activating solutions of the electroless plating of polymers: Potentiostatic operation, Sep. and Purif. Technol., 45 (2005) 183-191.

[21] Pérez-Herranz, V.; Guiñón, J.L.; García-Antón, J., Ingeniería Electroquímica, Servicio de Publicaciones Universitat Politècnica de València (ed.), 1997, 107195.

[22] E. Gómez, X. Alcobe, E. Vallés, Characterisation of zinc + cobalt alloy phases obtained by electrodeposition, J. of Electroanal. Chem., 505 (2001) 54-61.

[23] H. Dahms, I. M. Croll, The Anomalous Codeposition of Iron-Nickel Alloys, J. Electrochem. Soc., 112 (1965) 771-775.

[24] García-Gabaldón, M.; Carrillo-Abad, J.; Pérez-Herranz,V .; Ortega-Navarro, E. M., Electrochemical Study of a Simulated Spent Pickling Solution, Int. J. Electrochem. Sci., 6 (2011) 506-519. 


\section{LIST OF TABLES.}

Table 1: Average composition, in $\mathrm{mol} / \mathrm{l}$ and $\mathrm{g} / \mathrm{l}$, of the spent pickling bath used in this work. 


\section{LIST OF FIGURES.}

Fig. 1: Schematic representation of both reactors used and the reactions that may occur. The OCR is represented at the left picture and the membrane reactor at the right one.

Fig. 2: Comparison of zinc conversion profile for both reactors and for the 1:50 diluted spent pickling bath.

Fig. 3: Comparison of iron conversion profile for both reactors and for the 1:50 diluted spent pickling bath.

Fig. 4: Comparison of bulk $\mathrm{pH}$ profile for both reactors and for the 1:50 diluted spent pickling bath.

Fig. 5: Evolution of zinc current efficiency for both reactors and for the 1:50 diluted spent pickling bath.

Fig. 6: Evolution of zinc space-time yield with time for both reactors and for the 1:50 diluted real spent pickling bath.

Fig. 7: Evolution of zinc specific energy consumption with time for both reactors for the 1:50 diluted spent pickling bath.

Fig. 8: Comparison of zinc conversion profile for both electrochemical reactors and both initial cathodic solutions. 1:10 spent pickling bath.

Fig. 9: Comparison of iron conversion profile and the zinc-iron ratio for both electrochemical reactors and both initial cathodic solutions. 1:10 spent pickling bath.

Fig. 10: Comparison of zinc-iron ratio for both electrochemical reactors and both initial cathodic solutions. 1:10 spent pickling bath.

Fig. 11: Comparison of $\mathrm{pH}$ profile for both electrochemical reactors and both initial cathodic solutions. 1:10 spent pickling bath.

Fig. 12: Evolution of zinc current efficiency with time for both reactors and both initial cathodic solutions. 1:10 diluted real spent pickling bath.

Fig. 13: Evolution of zinc space-time yield with time for both reactors and both initial cathodic solutions. 1:10 diluted real spent pickling bath.

Fig. 14: Evolution of zinc specific energy consumption with time for both reactors and both initial cathodic solutions. 1:10 diluted real spent pickling baths. 
Table 1: Average composition, in $\mathrm{mol} / \mathrm{l}$ and $\mathrm{g} / \mathrm{l}$, of the spent pickling bath used in this work

\begin{tabular}{|l|c|c|c|}
\cline { 2 - 4 } \multicolumn{1}{c|}{} & $\mathbf{Z n}$ & $\mathbf{F e}$ & HCl \\
\hline $\mathbf{M}$ & 1.9780 & 1.0578 & 2.1380 \\
\hline $\mathbf{g} / \mathbf{l}$ & 129.3242 & 58.8129 & 78.0356 \\
\hline
\end{tabular}



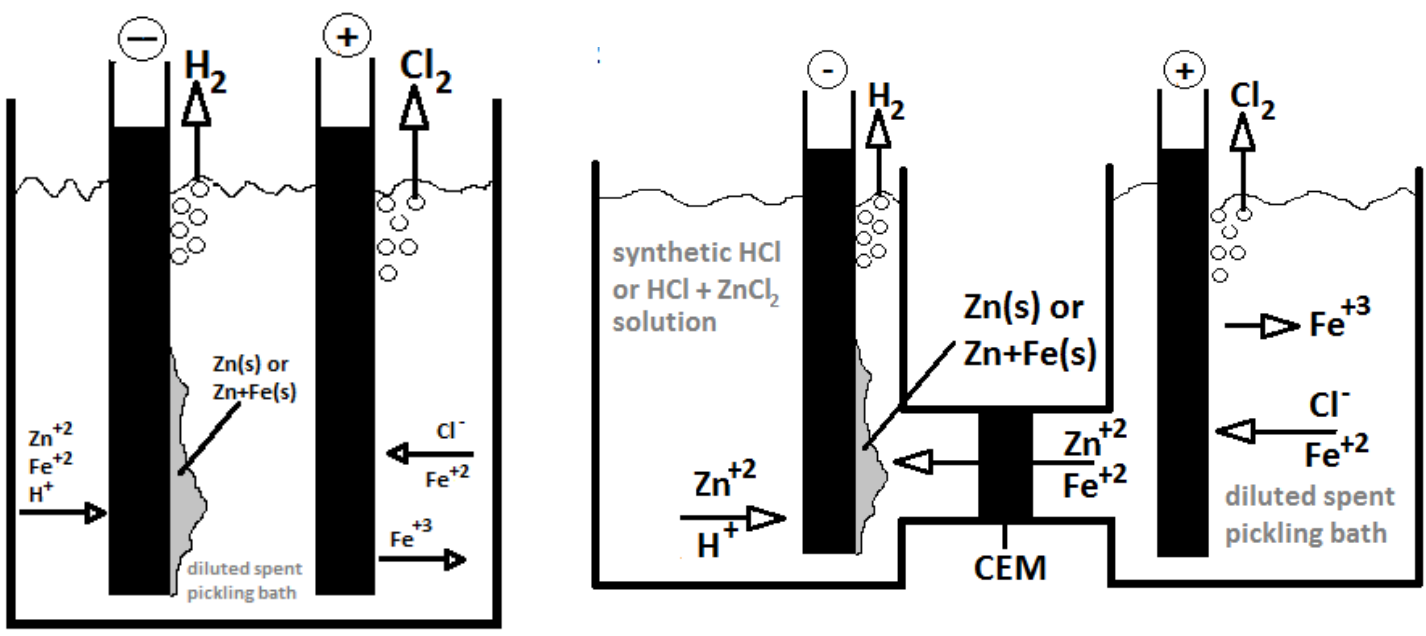

Fig. 1: Schematic representation of both reactors used and the reactions that may occur. The OCR is represented at the left picture and the membrane reactor at the right one. 


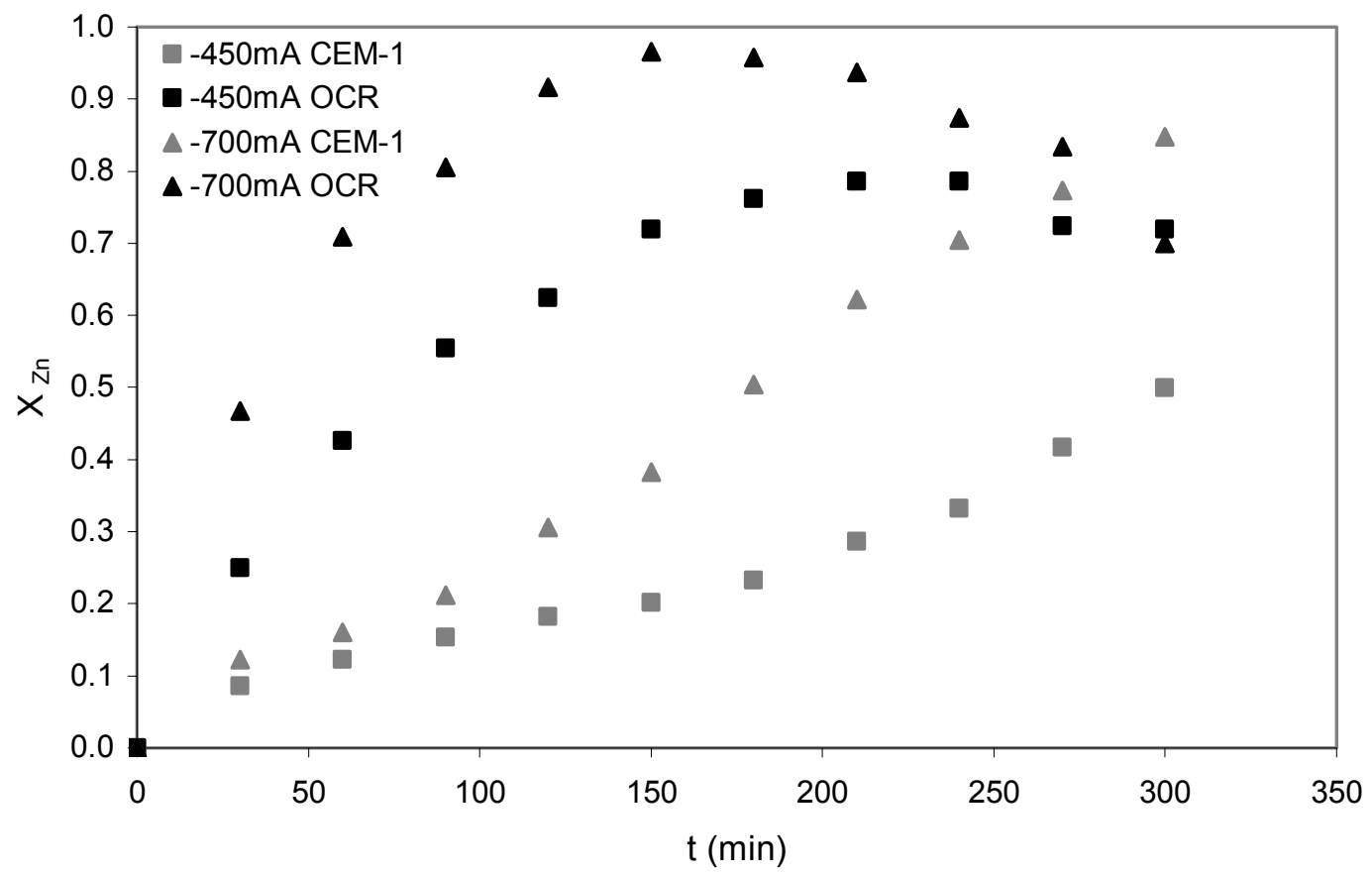

Fig. 2: Comparison of zinc conversion profile for both reactors and for the 1:50 diluted spent pickling bath. 


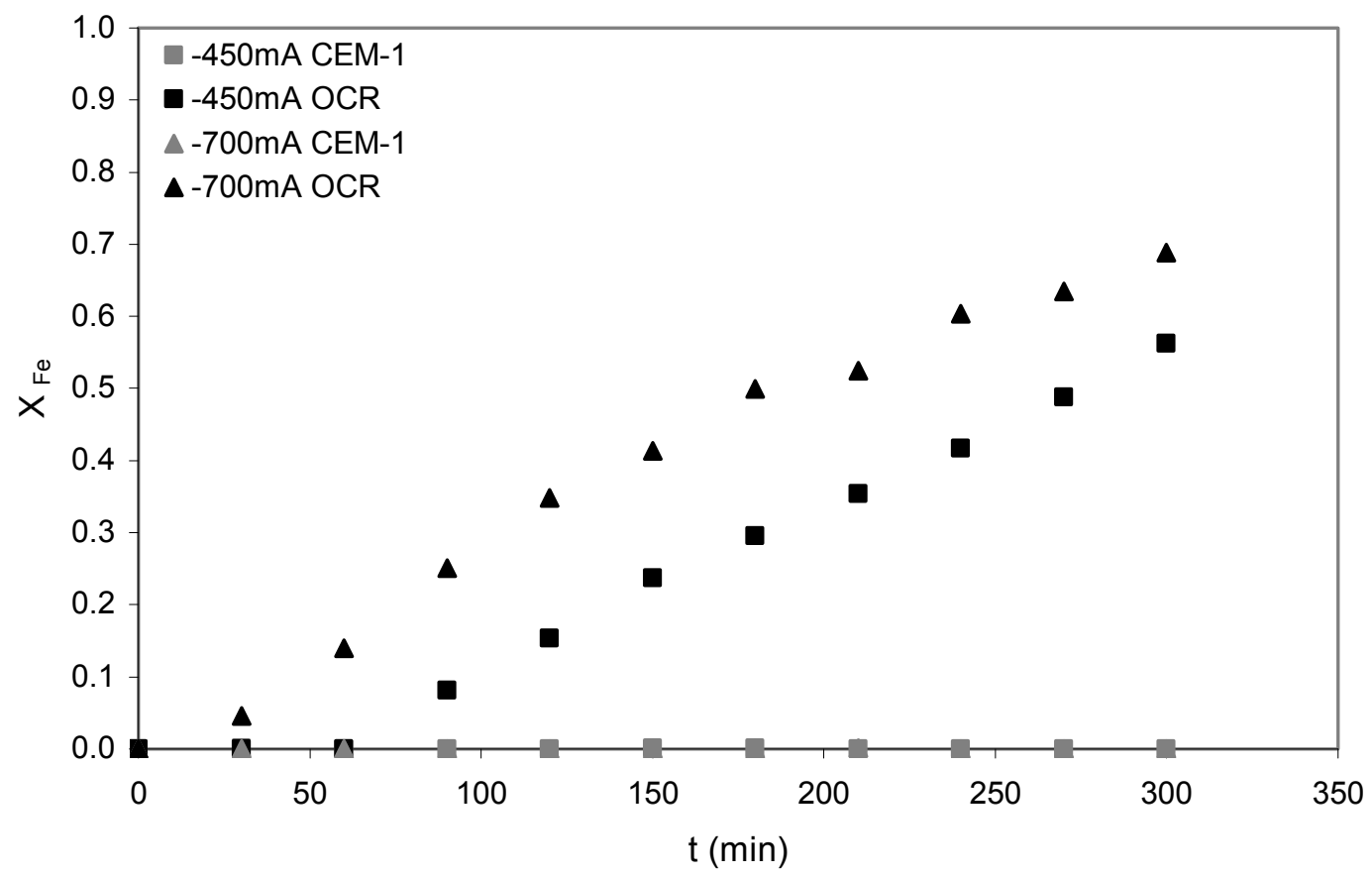

Fig. 3: Comparison of iron conversion profile for both reactors and for the 1:50 diluted spent pickling bath. 


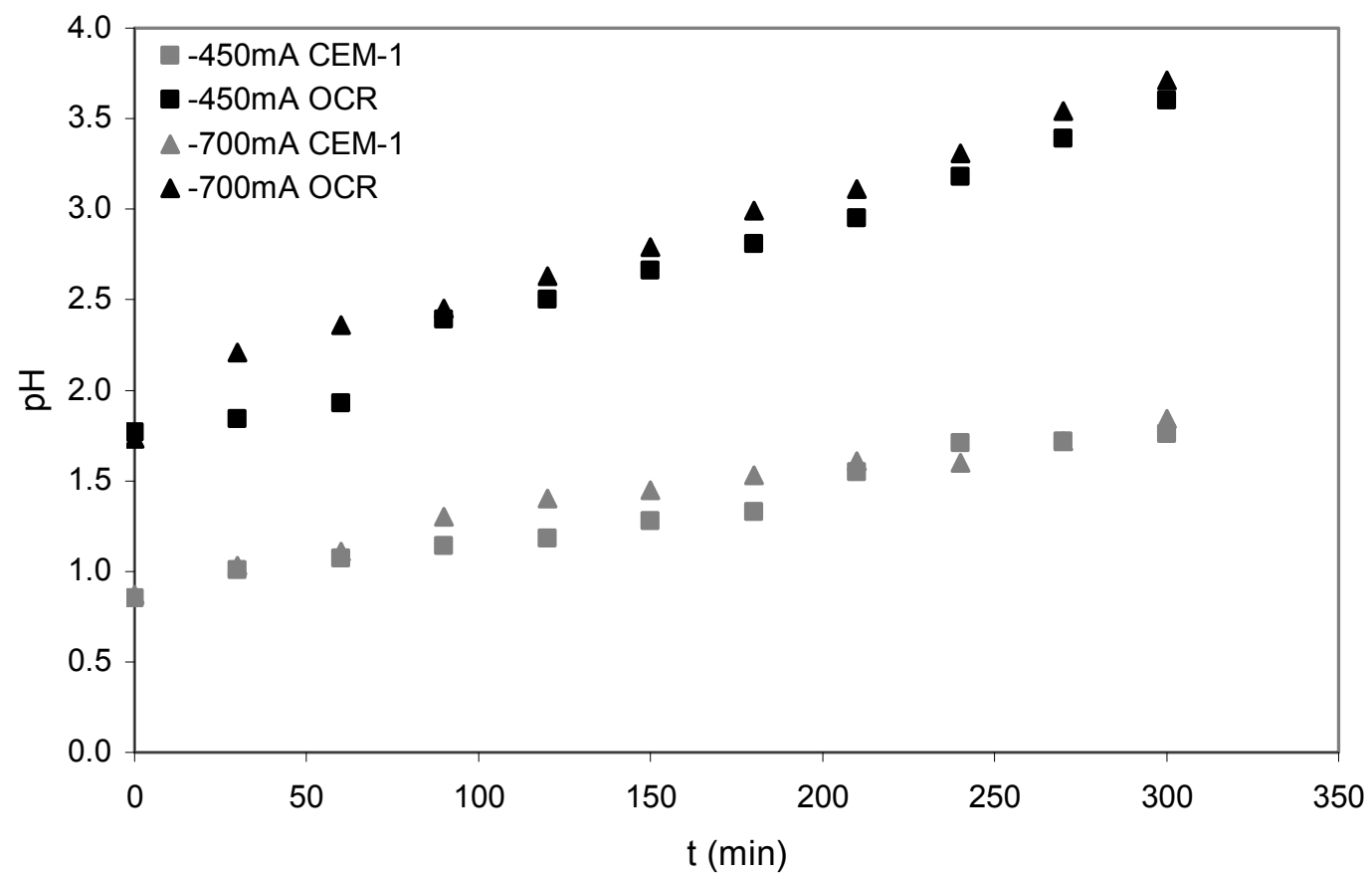

Fig. 4: Comparison of bulk $\mathrm{pH}$ profile for both reactors and for the 1:50 diluted spent pickling bath. 


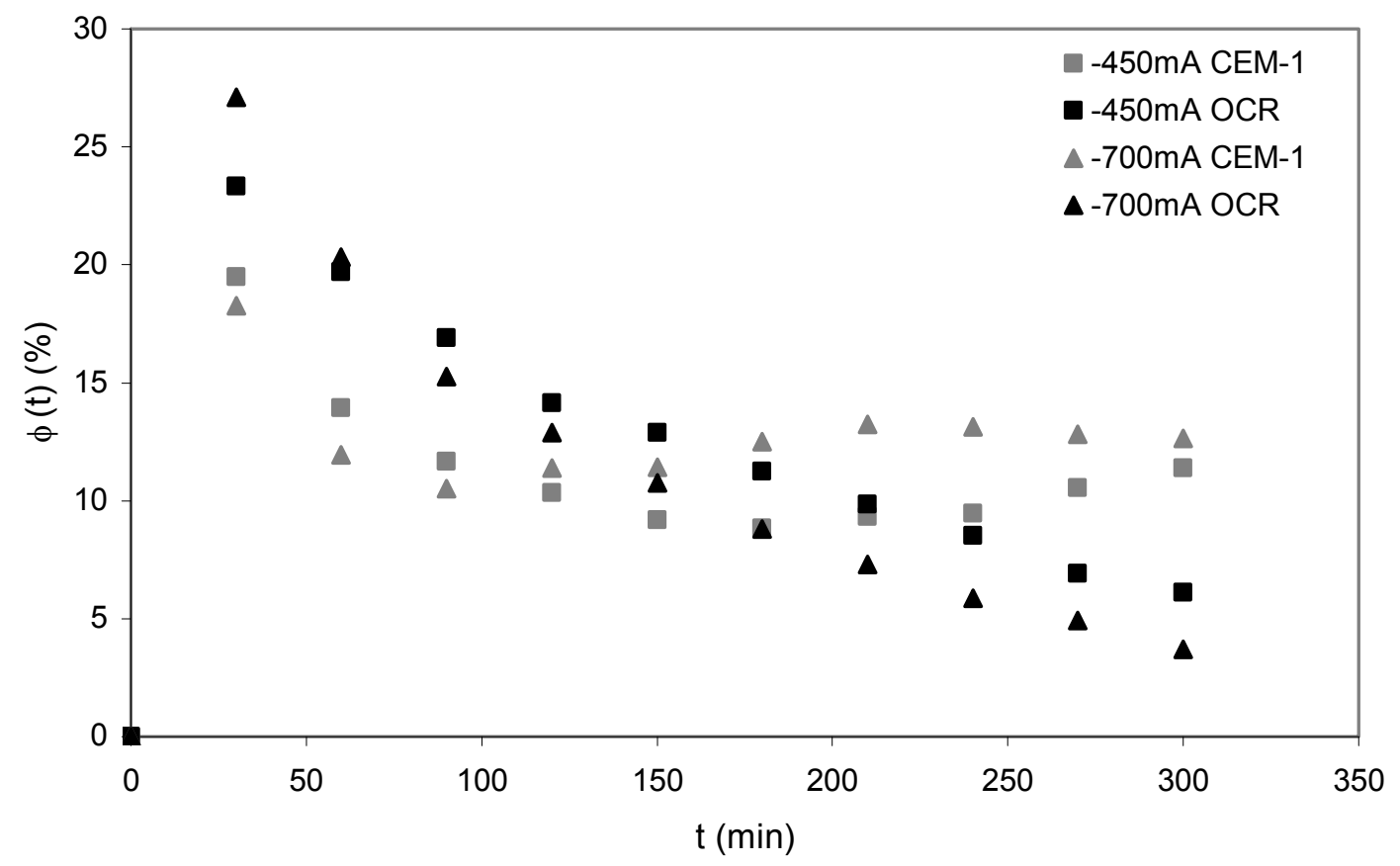

Fig. 5: Evolution of zinc current efficiency for both reactors and for the 1:50 diluted spent pickling bath. 


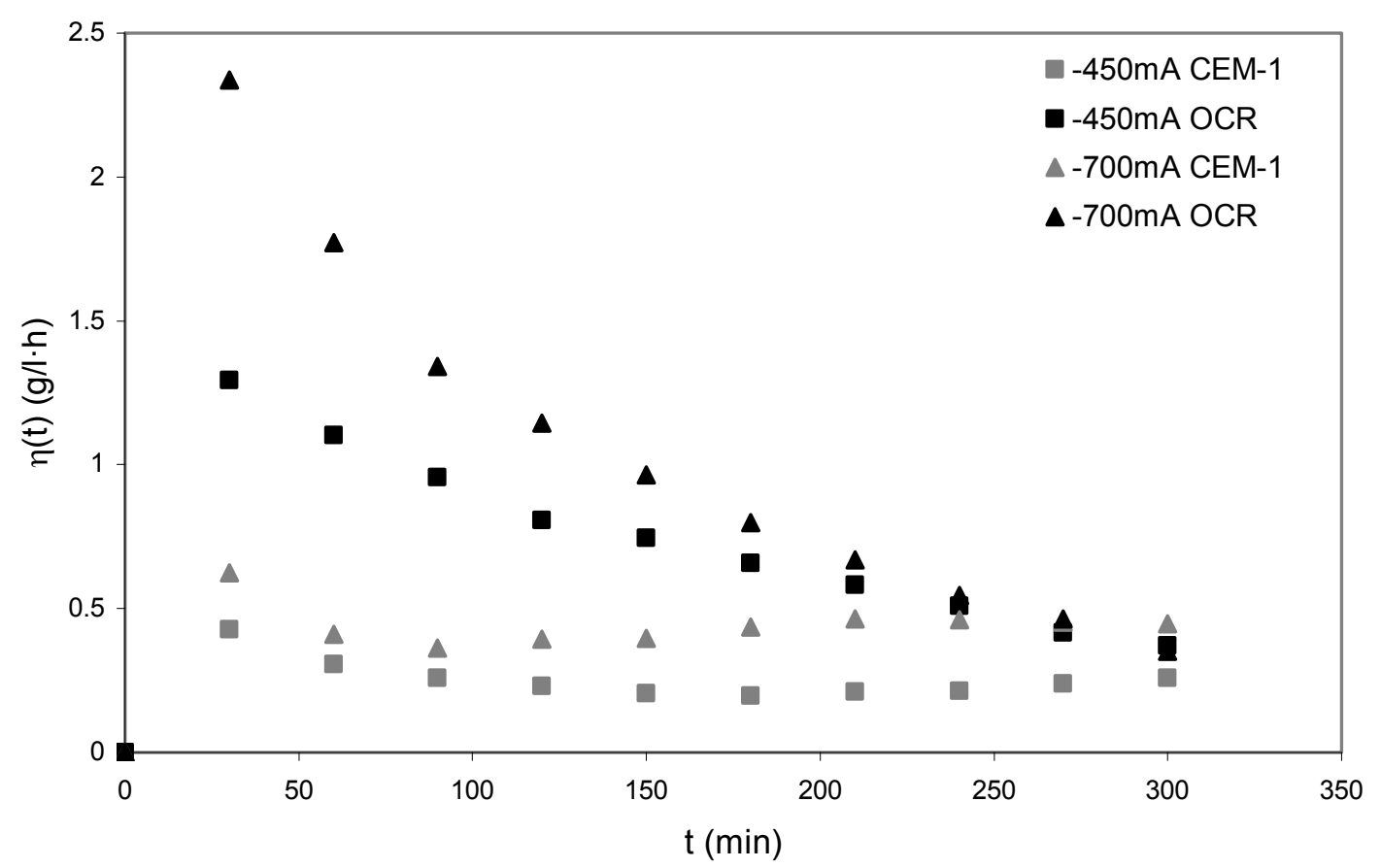

Fig. 6: Evolution of zinc space-time yield with time for both reactors and for the 1:50 diluted real spent pickling bath. 


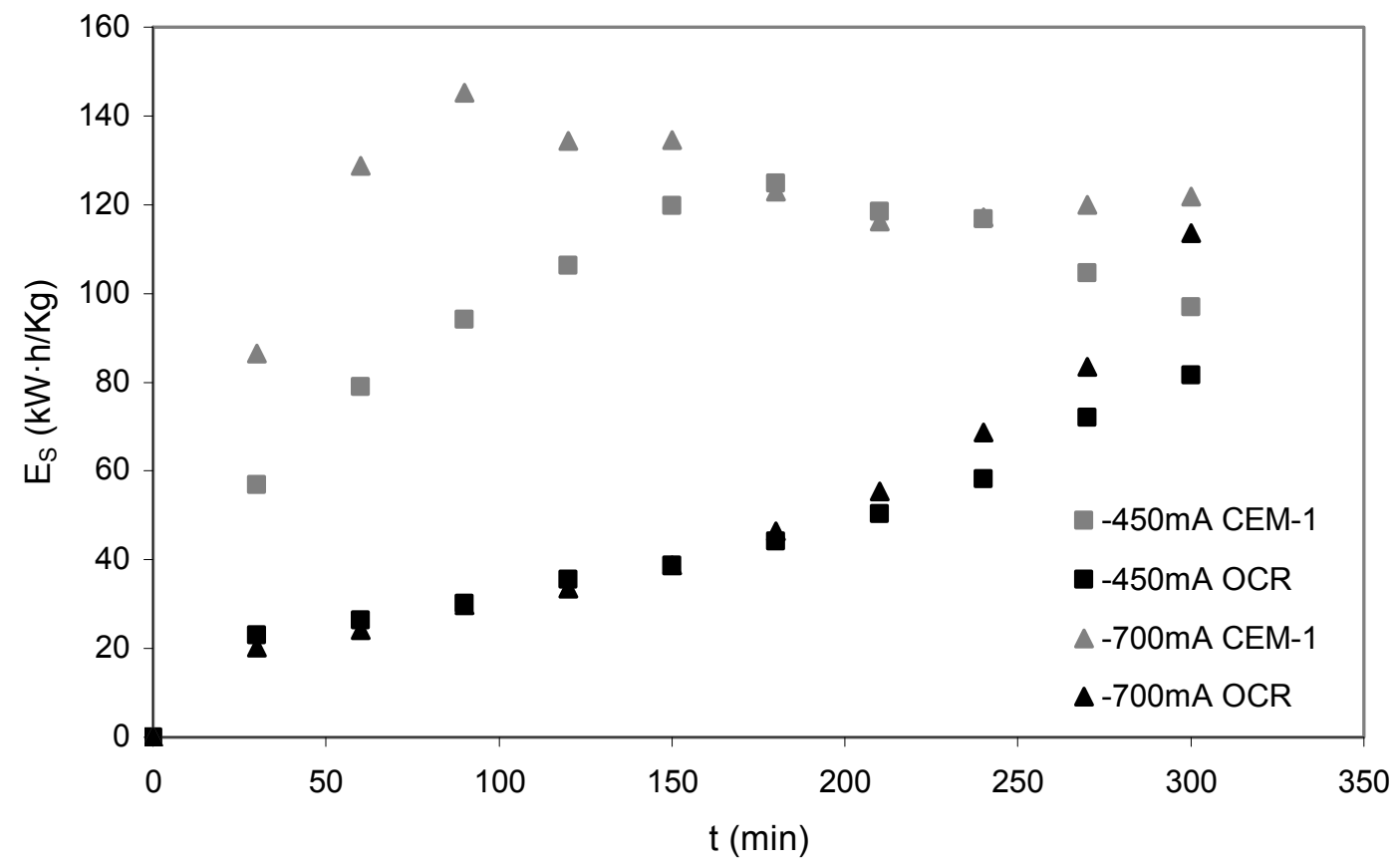

Fig. 7: Evolution of zinc specific energy consumption with time for both reactors for the 1:50 diluted spent pickling bath. 


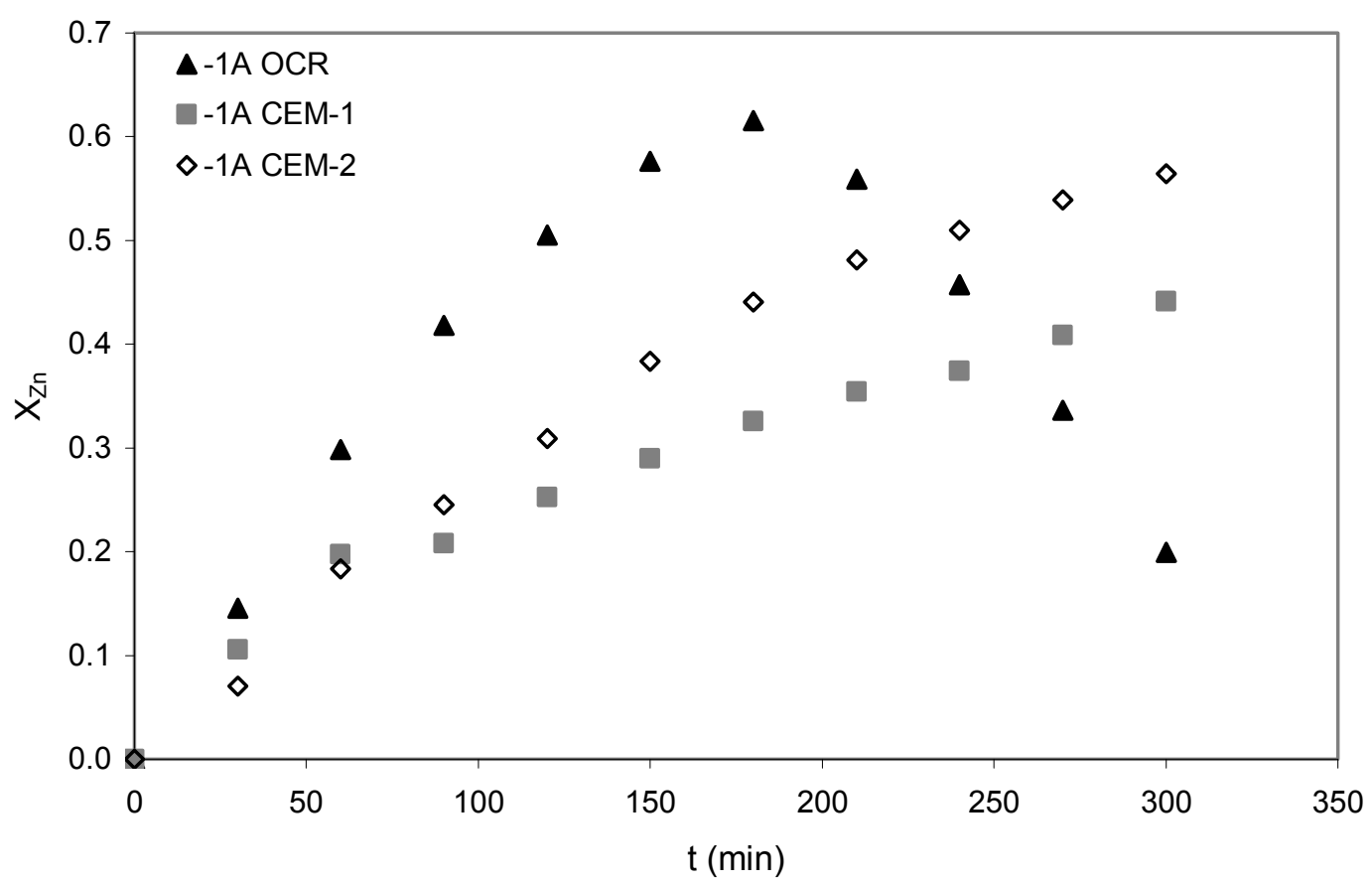

Fig. 8: Comparison of zinc conversion profile for both electrochemical reactors and both initial cathodic solutions. 1:10 spent pickling bath. 


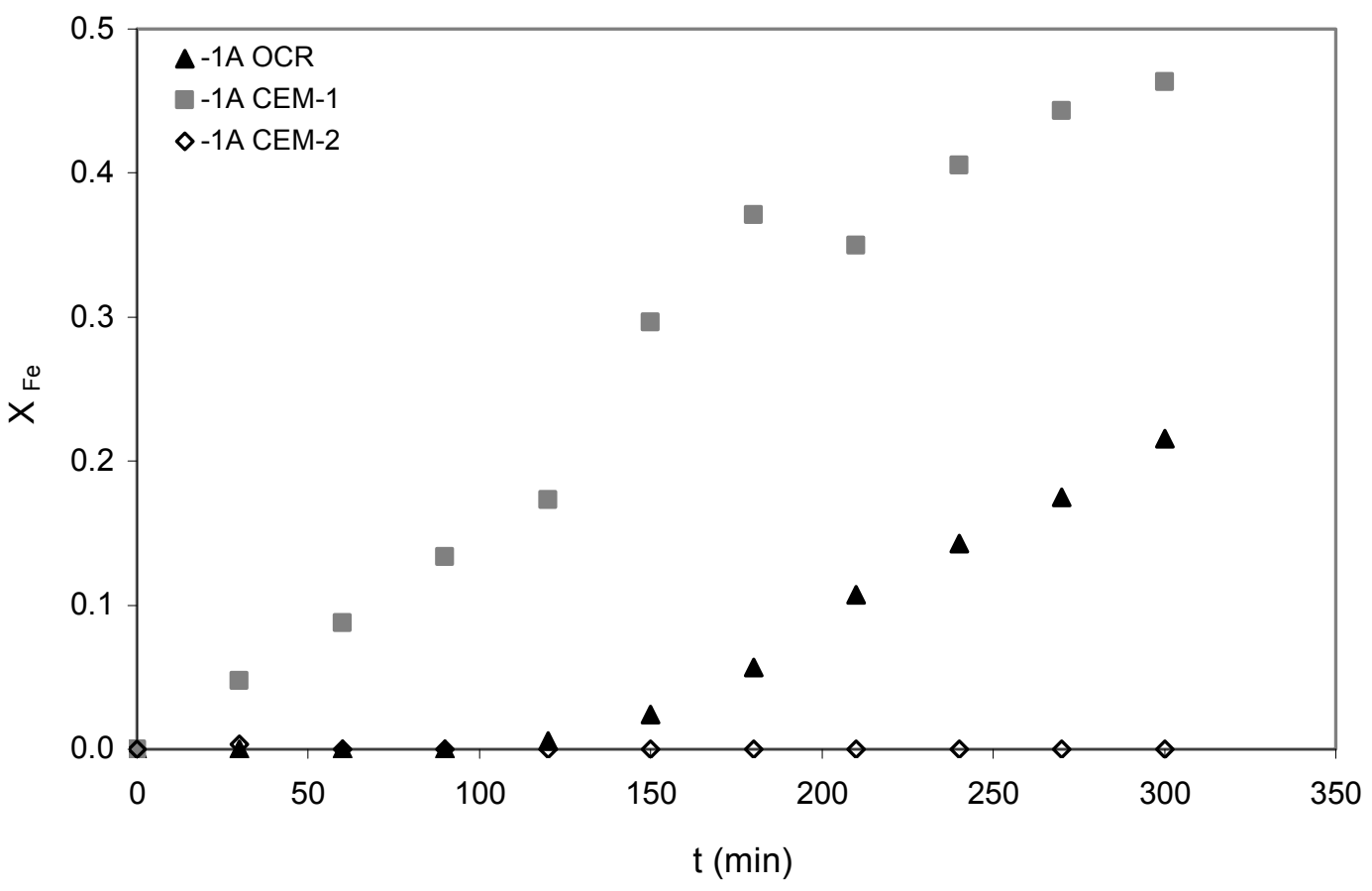

Fig. 9: Comparison of iron conversion profile and the zinc-iron ratio for both electrochemical reactors and both initial cathodic solutions. 1:10 spent pickling bath. 


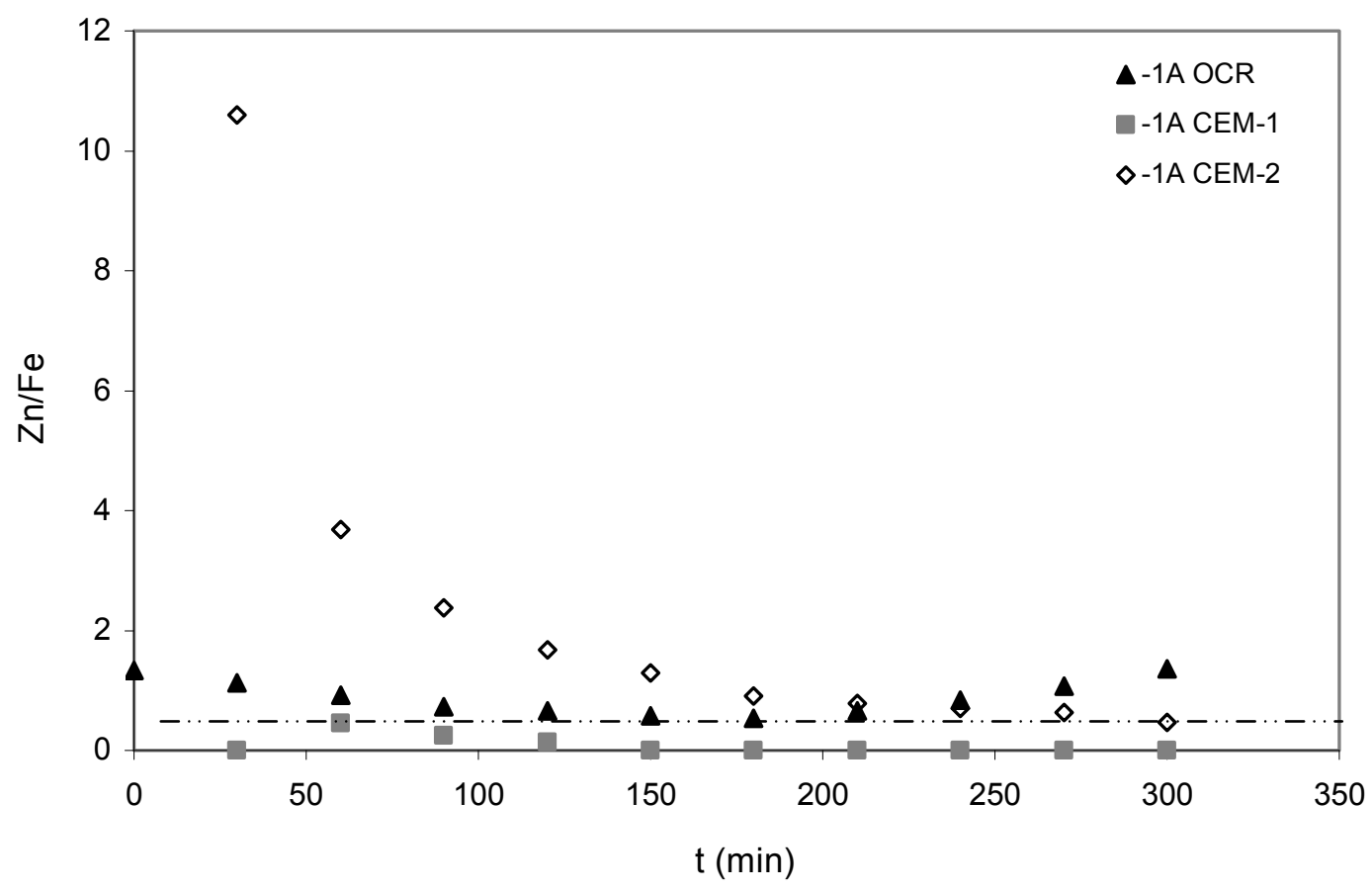

Fig. 10: Comparison of zinc-iron ratio for both electrochemical reactors and both initial cathodic solutions. 1:10 spent pickling bath. 


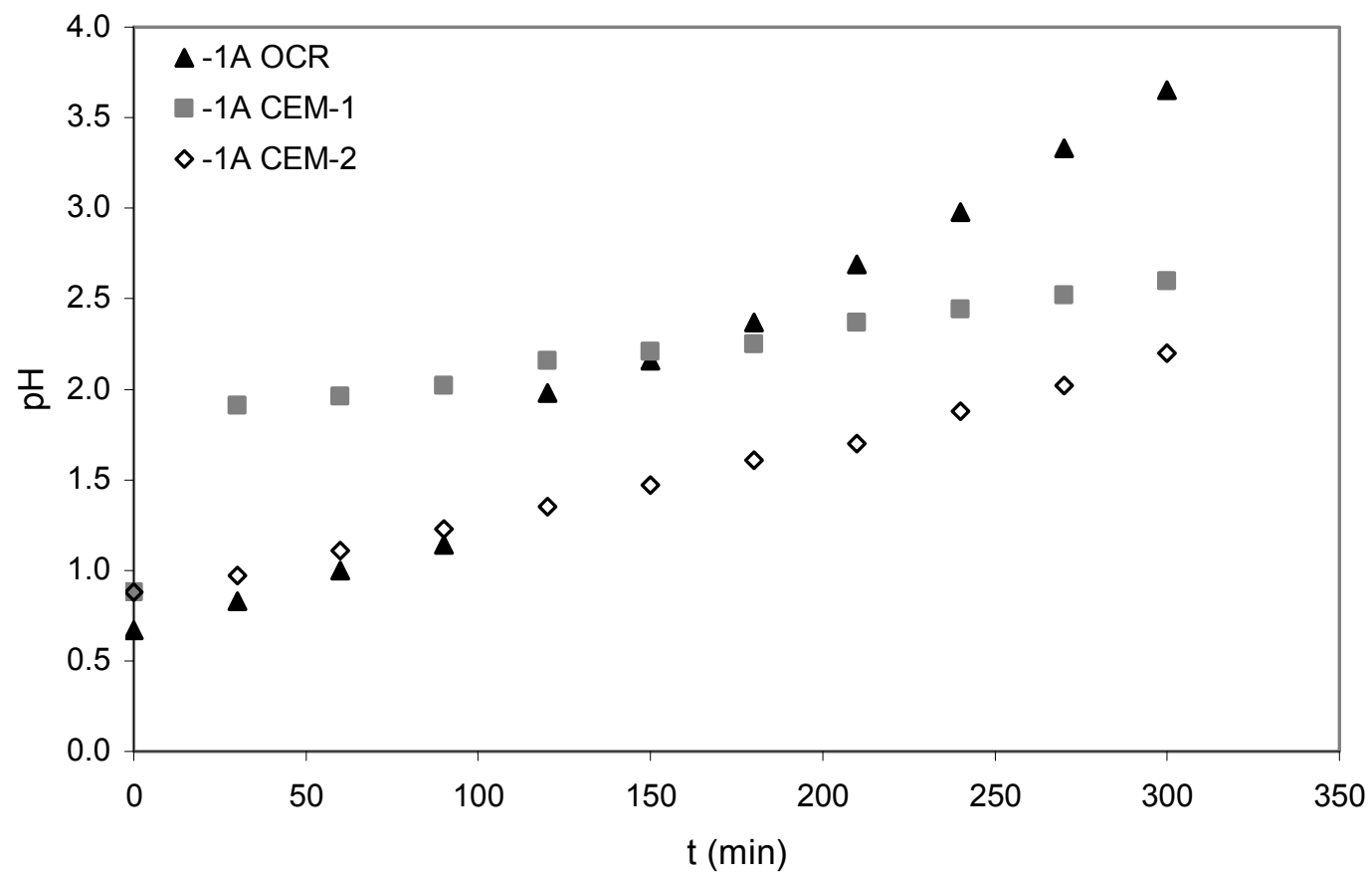

Fig. 11: Comparison of $\mathrm{pH}$ profile for both electrochemical reactors and both initial cathodic solutions. 1:10 spent pickling bath. 


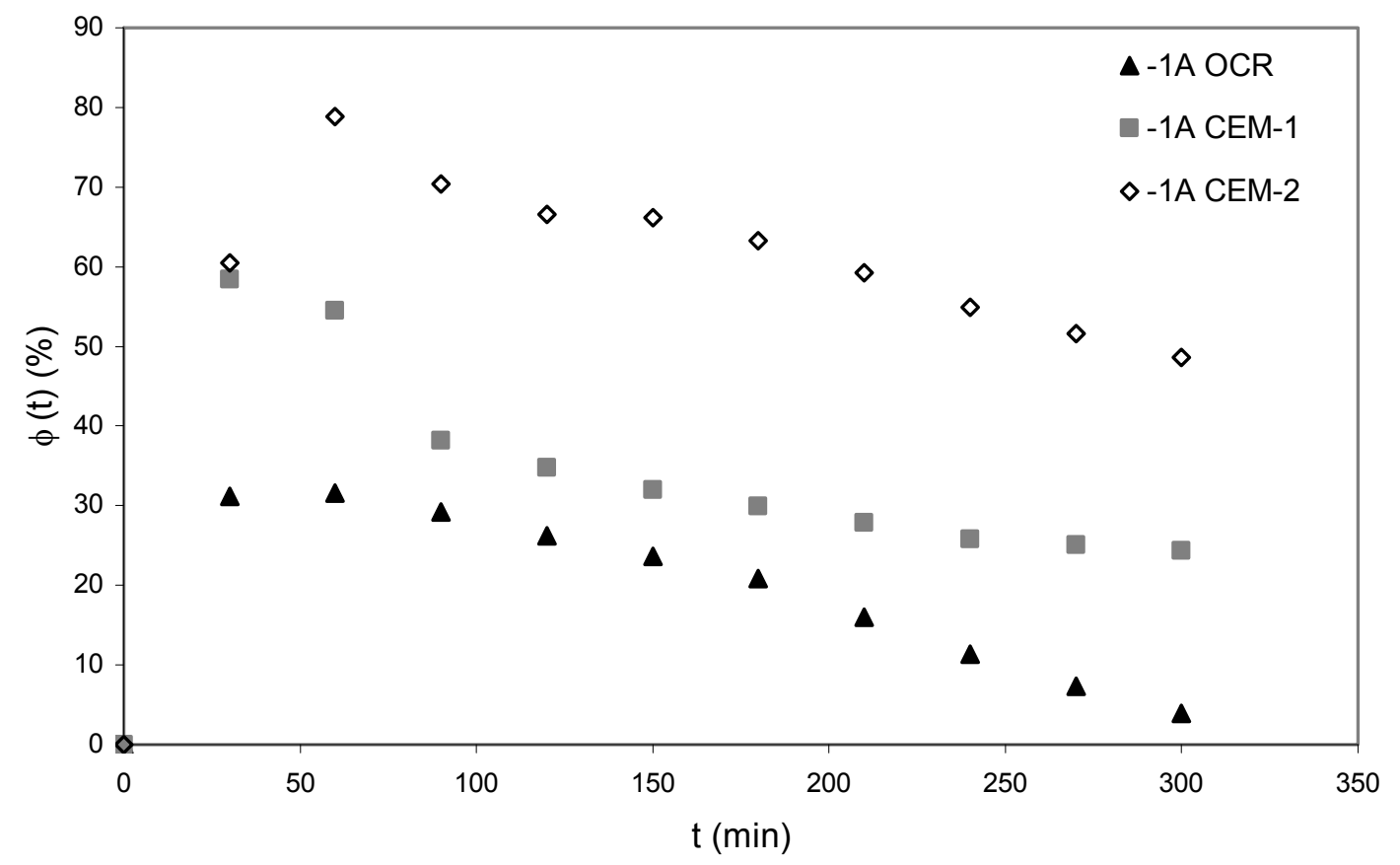

Fig. 12: Evolution of zinc current efficiency with time for both reactors and both initial cathodic solutions. 1:10 diluted real spent pickling bath. 


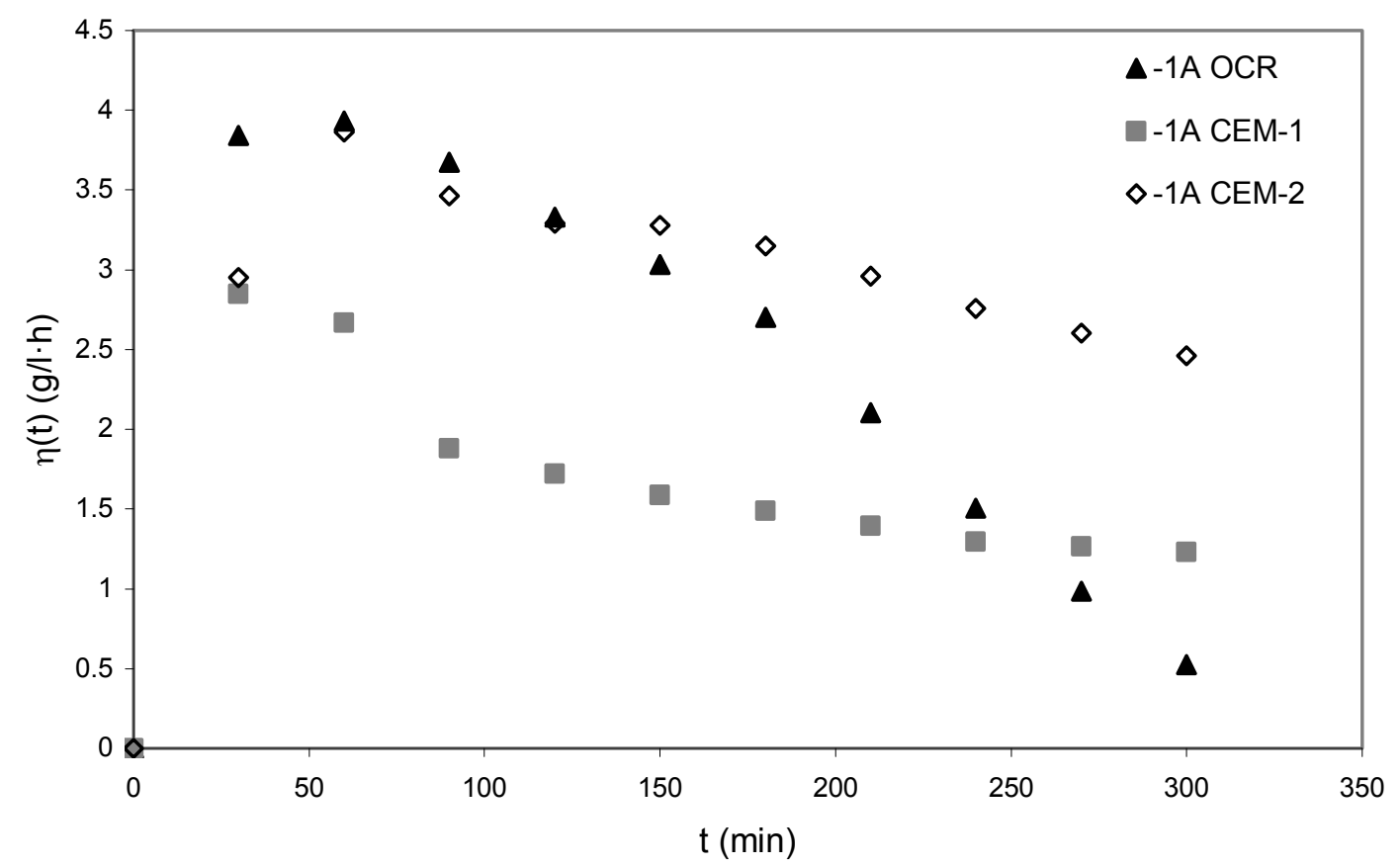

Fig. 13: Evolution of zinc space-time yield with time for both reactors and both initial cathodic solutions. 1:10 diluted real spent pickling bath. 


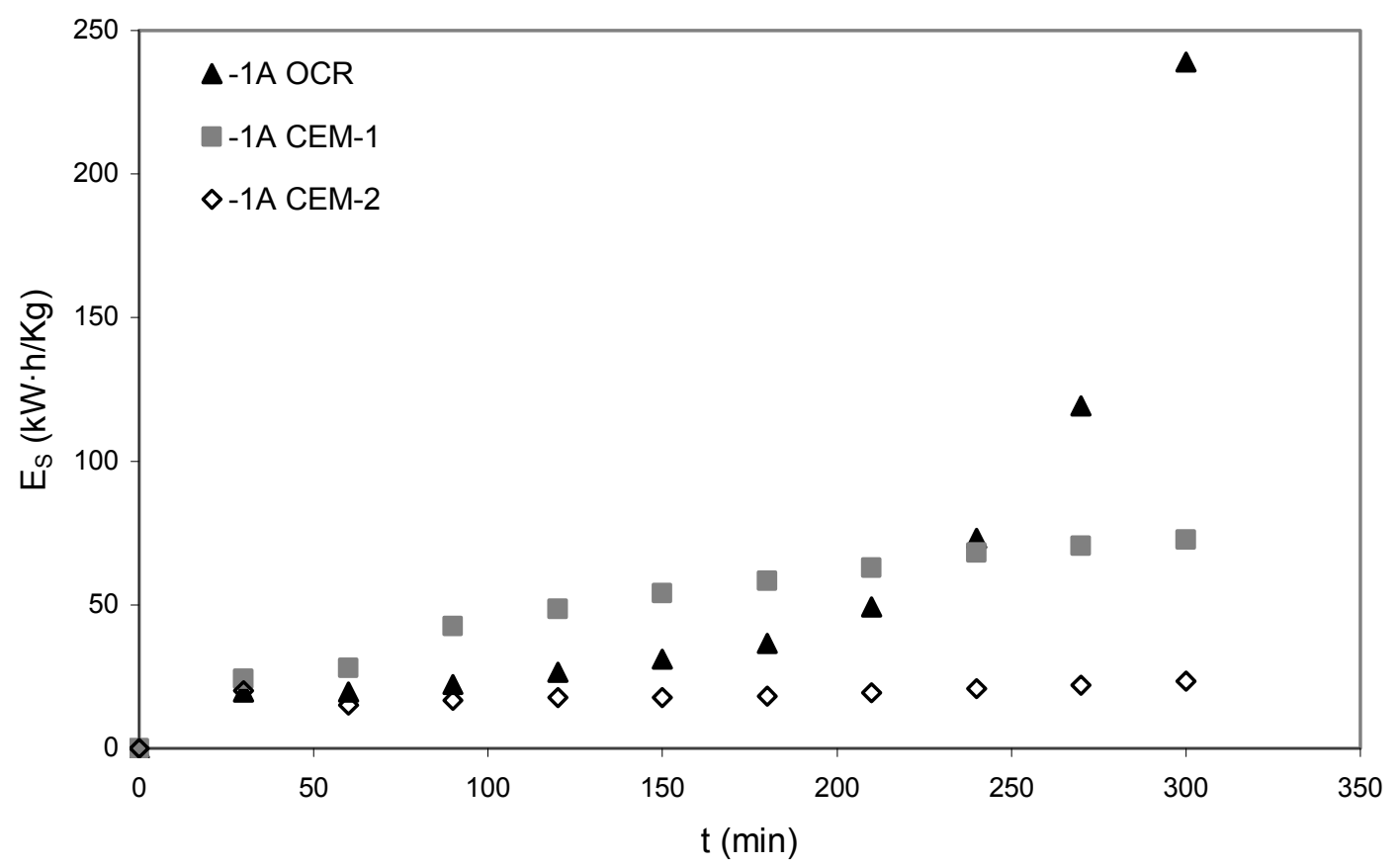

Fig. 14: Evolution of zinc specific energy consumption with time for both reactors and both initial cathodic solutions. 1:10 diluted real spent pickling baths. 